\title{
Conservación ex situ de plantas en el banco de germoplasma SAG-Magallanes: una herramienta para la Restauración Ecológica
}

\author{
Ex situ plant conservation in the SAG \\ germplasm bank: a tool for ecological restoration
}

Roberto Niculcar $^{1}$, Karina Latorre ${ }^{1}$ \& Osvaldo J. Vidal ${ }^{2}$

La conservación, entendida como una disciplina dedicada a la protección, rescate, mantención, estudio y uso sustentable del patrimonio biológico, es vital para mantener la diversidad genética de especies de un país o región, así como sus interacciones y los procesos evolutivos que las originan. En este sentido, los bancos de germoplasma son instalaciones o centros para conservar recursos genéticos bajo condiciones favorables para prolongar su sobrevivencia, cuyo objetivo final corresponde a la conservación ex-situ de diversidad específica y genética. Estos bancos permiten la preservación en el tiempo y la valoración de los recursos genéticos mediante su estudio. Son la fuente o base del material para el desarrollo de nuevas variedades cultivables, de nuevas tecnologías biológicas o fuente de material para planes de restauración ecológica, entre múltiples posibilidades.

Los ecosistemas han estado permanentemente influenciados por agentes perturbadores de origen natural, sin embargo en la actualidad el principal agente perturbador es el ser humano (Fernández, 2010).

Los incendios forestales representan una causa significativa de pérdida del patrimonio natural y a su vez son un agente perturbador. Anualmente se queman entre 20.000 y 85.000 hectáreas de vegetación, afectando principalmente vegetación natural, perdiéndose tanto su biodiversidad como los bienes y servicios ecosistémicos y sociales que esa vegetación presta, modificando la estructura y composición de especies, afectando las dinámicas sucesionales, y perturbando interacciones ecológicas clave del sistema (CONAF, 2015, Vidal
\& Reif, 2011).

En el período 1985-2010 se han registrado al menos 29 incendios en el Parque Nacional Torres del Paine, todos ellos provocados por el ser humano, afectando a más de 30 mil hectáreas del área protegida, incluyendo los grandes incendios de los años 1985 y 2005 (Vidal \& Reif, 2011), que precedieron al incendio del 2011 (Ministerio del Medio Ambiente, 2012).

Este factor se traduce en una pérdida de funcionalidad del ecosistema de difícil recuperación. En la medida que la frecuencia e intensidad de los incendios forestales aumenta, la necesidad por recuperar los ecosistemas nativos es cada vez más patente (Fernández, 2010).

El Informe Diagnostico Incendio Parque Nacional Torres del Paine afectado por el incendio 2011-2012 recomendó identificar los individuos reproductivos, especialmente de las especies amenazadas o raras presentes en el Parque, y desarrollar los protocolos para su viverización y posterior reintroducción en áreas perturbadas del Parque. Los protocolos técnicos para la recolección de semillas, almacenaje y propagación deben ser desarrollados no sólo para especies arbóreas, sino que deben incluir una diversidad de especies

Dirección del Banco de Germoplasma: Laboratorio de análisis y diagnóstico SAG, Km 711/2 norte sin número, Punta Arenas. $>$

2 Laboratorio de Botánica "Edmundo Pisano", Instituto de la Patagonia, Universidad de Magallanes. Av. Bulnes 01890, Punta Arenas, Chile. osvaldo.vidal@umag.cl 
arbustivas y herbáceas. Al respecto los protocolos realizados por el Banco de germoplasma del Servicio Agrícola y Ganadero (SAG) en cuanto a los procesos de conservación y manejo de información asociada a las semillas corresponden a los recomendados por la FAO en las Normas para Bancos de Genes de Recursos Fitogenéticos para la Alimentación y la Agricultura publicadas el año 2013.

Esta forma de conservación permite preservar la variabilidad genética de especies que pueden desaparecer a nivel local. Esta

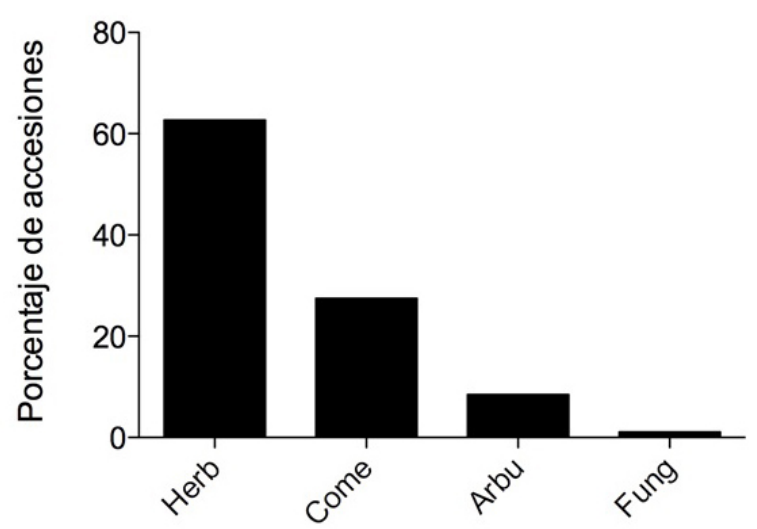

Fig. 1. Distribución porcentual de las accesiones conservadas desde el 2010 a Enero del 2015 en el Banco de Germoplasma del SAG según formas de vida y uso (Herb= herbáceas;

Come $=$ variedade comerciales; Arbu $=$ arbustivas y arborescentes; Fung= hongos).

a) Origen Fitogeográfico Accesiones

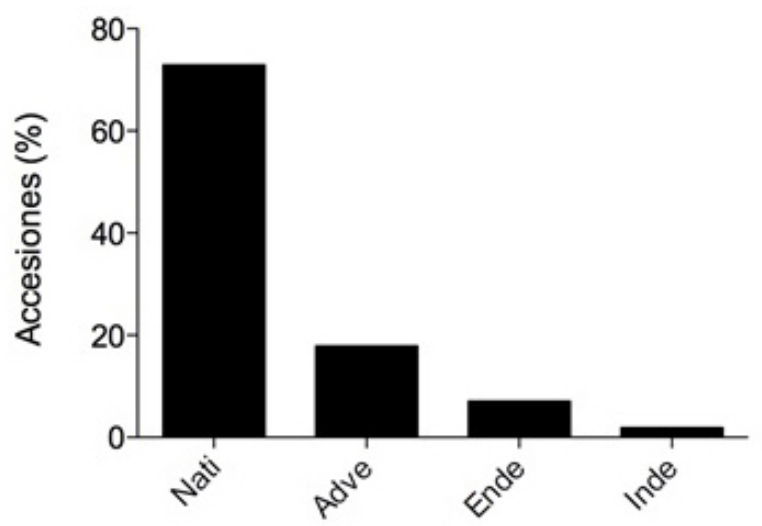

extinción de poblaciones, representa una pérdida irreparable de su material genético. El SAG en su labor de contribuir al desarrollo productivo y al mejoramiento de la competitividad del Sector Agrícola, Ganadero y Forestal, habilitó el Banco de Germoplasma Región de Magallanes y Antártica Chilena, con fondos del Gobierno Regional (equipos) y el aporte institucional (infraestructura, operaciones y personal), en Marzo del 2010. Esta unidad puede conservar hasta 100.000 entradas de semillas (sobres con semillas colectadas en una fecha y lugar determinado) y 21.000 crioviales con tejido conservado en nitrógeno.

La presente nota científica tiene por objetivo mostrar el detalle del material conservado a la fecha, y su distribución de acuerdo a sus formas de vida y uso, origen geográfico y provincia política. Por otro lado, se muestran las acciones concretas realizadas a la fecha en restauración ecológica del Parque Nacional Torres del Paine.

\section{El banco de germoplasma SAG}

El Banco de Germoplasma SAG de la Región de Magallanes y Antártica Chilena es el más austral del mundo y uno de los más modernos de Sudamérica. Este banco conserva en forma ex-situ especies de plantas nativas y

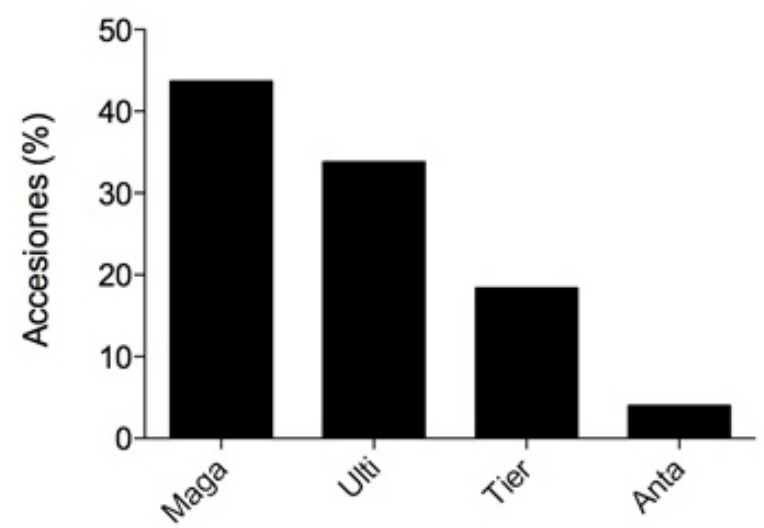

Fig. 2. Distribución de accesiones de plantas herbáceas nativas y naturalizadas conservadas a la fecha según su origen geográfico (2a), con un universo total de 9.302 accesiones y según la provincia política (2b) de la región de Magallanes y Antártica Chilena (Nati= nativas; Adve= advenas; Ende= endémicas; Inde= indeterminadas; Maga= Provincia de Magallanes; Ulti= Provincia de Última Esperanza; Tier= Provincia de Tierra del Fuego; Anta= Provincia Antártica). 
Tabla 1. Resumen del número de accesiones conservadas del año 2010 a Enero del 2015, según el tipo de accesión en el Laboratorio de Germoplasma del SAG.

\begin{tabular}{llllll}
\hline Tipo de accesión & $\begin{array}{l}\text { División Semillas } \\
\text { SAG }\end{array}$ & $\begin{array}{l}\text { Herbáceas nativas y } \\
\text { naturalizadas }\end{array}$ & $\begin{array}{l}\text { Arbustivas y arbóreas } \\
\text { nativas }\end{array}$ & Hongos & Total \\
\hline $\begin{array}{l}\text { Número de accesiones } \\
\text { conservadas }\end{array}$ & 3853 & 8157 & 1116 & 152 & 13008 \\
$\begin{array}{l}\text { Número de familias } \\
\text { conservadas }\end{array}$ & 6 & 29 & 25 & 15 & 85 \\
$\begin{array}{l}\text { Número de géneros } \\
\text { conservados }\end{array}$ & 19 & 131 & 35 & 21 & 206 \\
$\begin{array}{l}\text { Número de especies } \\
\text { conservadas }\end{array}$ & 29 & 190 & 44 & 26 & 289 \\
$\begin{array}{l}\text { Número de variedades } \\
\text { comerciales conservadas }\end{array}$ & 251 & 0 & 0 & 0 & 251 \\
\hline
\end{tabular}

especies comerciales vigentes y obsoletas para las futuras generaciones, a través de tres formas de conservación: semillas conservadas en frío, tejidos vegetales in vitro y crio-conservación en nitrógeno líquido. La Tabla 1 muestra el resumen del número de accesiones conservadas del año 2010 a Enero del 2015, según el tipo de accesión en el Laboratorio de Germoplasma del SAG. Desde el año 2009 hasta el presente (2015) se han conservado poco más de 13.000 accesiones, las cuales representan plantas de 85 Familias y 206 géneros, lo que se traduce en la conservación de un total de 289 especies vegetales (Figs. 1 y 2 ).

Proponemos que el material nativo conservado, como la información generada a partir del manejo del mismo (e.g. determinación de protocolos de germinación y viverización), puede ser utilizado como una poderosa herramienta para la restauración ecológica en ecosistemas degradados en la Región de Magallanes y en particular del Parque Nacional Torres del Paine. Durante los últimos años, el Laboratorio de Germoplasma del SAG ha generado numerosos protocolos de germinación y viverización de especies de plantas nativas, algunas de ellas sensibles a los incendios (e.g. sin capacidad de rebrote post-fuego), por lo que esta información puede representar un recurso valioso para re-introducir especies en ecosistemas con baja resiliencia al fuego, y promover con ello funciones ecosistémicas debilitadas o perdidas en los ecosistemas degradados de Torres del Paine.
Acciones del banco de germoplasma a la restauración ecológica del Parque Nacional Torres del Paine (PNTP)

El material conservado en forma ex situ perteneciente al PNTP a la fecha, corresponde a 2.420 sobres con semillas, las cuales pueden ser utilizadas para reinsertar poblaciones en planes de restauración ecológica. El año 2014 se trabajó en la primera fase del proyecto de "Implementación de Acciones de Restauración Ecológica" financiado por el Ministerio del Medio Ambiente y ejecutado por el Centro EULA de la Universidad de Concepción. Este proyecto permitió conservar 1.087 accesiones (sobres con semillas) de 79 especies presentes en el PNTP. De estas el $42 \%$ corresponde a especies que no se habían colectado nunca antes en el PNTP, por lo tanto no tenían ningún tipo de conservación ex-situ. Respecto a los sitios de colecta, del total de sobres colectados, un $58 \%$ fue colectado en sectores que fueron afectados por incendios (años 1985, 2005 y 2012).

El material colectado en este proyecto, fue utilizado para generar plantas que serán utilizadas en ensayos de restauración ecológica en la segunda etapa del proyecto (año 2015). Particularmente se trabaja en el desarrollo de protocolos de viverización de tres especies endémicas de la Patagonia que presentan bajo nivel de regeneración natural y/o rebrote post fuego (Adesmia borionioides, Anarthrophyllum desideratum y Junellia tridens).

Los bancos de germoplasma son una 
herramienta real y concreta para planes de restauración ecológica debido a que parte del material conservado puede ser utilizado para regenerar germoplasma; es decir, ser cultivado en invernadero y a partir de este generar más semillas las cuales pueden ser utilizadas en restauración, o producir plantas que sean utilizadas directamente para restaurar.

El material conservado debe ser evaluado en el tiempo (capacidad germinativa), lo cual implica la determinación de protocolos de germinación y/o viverización. Esta información es fundamental toda vez que se consideren estas especies en los planes de restauración.

Las semillas conservadas pueden ser utilizadas en estudios genéticos. En estos momentos no sabemos la variabilidad genética de cada especie y si éstas son significativas de acuerdo a distancias geográficas. Esto cobra relevancia al momento de diseñar planes de restauración debido a que se desconoce los efectos ecológicos de la introducción de material genético al PNTP procedentes de otras áreas de la Región.

Es fundamental seguir incrementando $y$ conservando ex situ el número de accesiones de especies nativas presentes en el Parque Nacional Torres del Paine, como una forma complementaria a la conservación in situ realizada, ya que esta forma de conservación no asegura la permanencia en el tiempo de especies nativas, debido principalmente al peligro constante de incendios de origen antrópico.

\section{LITERATURA CITADA}

Alercia, A., Diulgheroff, S. \& Metz, T. (2001). FAO/ IPGRI. Multi-crop Passport Descriptors

Armesto, J.J., Rozzi, R., Smith-Ramírez, C., \& Arroyo M.T.K. (1998). Conservation targets in South-American Temperate forests. Science, 282, 1271-1272.

Bannister, J, Vidal, O.J., Teneb, E. \& Sandoval, V. (2012). Latitudinal patterns and regionalization of plant diversity along a $4270-\mathrm{km}$ gradient in continental Chile. Austral Ecology, 37, 500-509.

CONAF (2015) Estadísticas Resumen Nacional Número y Superficie Afectada por Incendios Forestales 1964 - 2014, http://www.conaf. $\mathrm{cl} /$ incendios-forestales/incendios-forestalesen-chile/estadisticas-historicas/

FAO (2013). Genebank Standards for Plant Genetic Resources for Food and Agriculture. Rome.

Fernández, I., Morales N., Olivares, L., Salvatierra, J., Gómez, M. \& Montenegro, G. (2010). Restauración ecológica para ecosistemas nativos afectados por incendios forestales, Pontificia Universidad Católica.

Gold, K., León-Lobos, P. \& Way, M. (2004). Manual de recolección de semillas de plantas silvestres para conservación a largo plazo y restauración ecológica. Instituto de Investigaciones Agropecuarias, Centro Regional de Investigación Intihuasi, La Serena, Chile. Boletín INIA N 110, 1-62

Mansilla, H. (2007). La comunidad de Junellia tridens y los efectos de fuego en el Parque Nacional Torres del Paine, Patagonia, Chile. Tesis de Licenciatura en Ciencias Biológicas, Facultad de Ciencias, Universidad de Magallanes.

Merritt, D.J. \& Dixon, K.W. (2011). Restoration Seed Banks: A Matter of Scale. Science, 332, 424-425.

Ministerio de Agricultura (2014). Conservación, acceso y valorización del patrimonio fitogenético, acciones y mejoras de Los bancos de germoplasma en Chile.

Ministerio del Medio Ambiente (2012). Plan de restauración ecológica del Parque Nacional Torres del Paine afectado por incendio 2011-2012.

Ministerio del Medio Ambiente (2014). Implementación de acciones de restauración ecológica en Torres del Paine - Fase I. Informe Final.

Labbé, D. (2013). Efecto del fuego sobre la viabilidad y germinación de semillas en ecosistemas Patagónicos, Universidad Austral de Chile, Facultad de Ciencias Forestales.

Paula, S. \& Labbé, D.L. (2012). Evaluación de los impactos del incendio Olguín (Parque Nacional Torres del Paine) en la vegetación. Informe del Instituto de Ciencias Ambientales y Evolutivas, Universidad Austral de Chile.

Primack, R. \& Massardo, F. (2001). Restauración Ecológica. En R. Primack, R. Rozzi, P. Feisinger, R. Dirzo \& F. Massardo. (Eds.). 
Fundamentos de Conservación Biológica (pp. 559-582). Fondo de Cultura Económica, México DF.

Rao, N. K., Hanson, J., Dulloo, M. E., Gosh, K., Novell, D. \& Larinde, M. (2007).

Manual para el manejo de semillas en Bancos de Germoplasma. Manuales para Banco de Germoplasma. No.8. Bioversity International, Roma, Italia.

Society for Ecological Restoration International
Science \& Policy Working Group (2004). The SER International Primer on Ecological Restoration. www.ser.org \& Tucson: Society for Ecological Restoration International. 15.

Vidal, O. \& Reif, A. (2011). Effect of a touristignited wildfire on Nothofagus pumilio forests at Torres del Paine Biosphere Reserve, Chile (Southern Patagonia). Bosque, 32, 64-76. 
